\title{
Role of Computed Tomography Scan in the Assessment of Subacute Intestinal Obstruction at Bhuj, Kutch: A Prospective Study
}

\author{
Ashvin Pansuriya ${ }^{\circledR}$ \\ Assistant Professor, Department of Radiology, Gujarat Adani Institute of Medical Sciences, Bhuj, Kutch, Gujarat, India.
}

\section{Abstract}

Background: Bowel obstruction occurs when the normal flow of intraluminal contents is interrupted. Obstruction can be functional or due to a mechanical obstruction. Now a day's CT is considered to be the most efficacious imaging technique for determining the cause of intestinal obstruction. However, the indications for the use of CT in patients with Sub-Acute Intestinal Obstruction (SAIO) have not been fully defined. Objectives of the present study are to study the role of CT in Diagnosis of patients with suspected subacute intestinal obstruction (SAIO), to find out site \& cause of obstruction and to diagnose complications of obstruction. Subjects and Methods: This study was conducted at Department of Radiodiagnosis, Gujarat Adani institute of Medcial Science, Bhuj, Kutch, Gujarat. Total number of 22 patients with SAIO having equivocal findings on USG was included in this study. Detailed clinical evaluation of the patients was done. Plain x-ray of abdomen in erect posture \& abdominopelvic ultrasound were performed before CT scan. CT scans were performed on a GE lightspeed VCT 64 slice scanner and acquired in precontrast \& portovenous phase at $60 \mathrm{sec}$ after i.v. contrast administration. Results: Age of the patients in the study range between 14 to 76 years. Out of 22 were 12 male \& 10 female patients. On CT scan all 22 patients were found to have obstruction with 19 patients having mechanical obstruction \& 3 patients having pseudo obstruction secondary to appendicitis, jejunal perforation. Most common cause of SAIO was ileal stricture $38 \%$ followed by intussusceptions $23 \%$. Conclusion: CT is not only useful in distinguishing mechanical obstruction from paralytic ileus but also it often establishes the cause of obstruction \& presence of complications like strangulation $\&$ perforation.

Keywords: Kutch, Ileus, Subacute intestinal obstruction, Perforation

Corresponding Author: Ashvin Pansuriya, Assistant Professor, Department of Radiology, Gujarat Adani Institute of Medical Sciences, Bhuj, Kutch, Gujarat, India.

E-mail: drpiyushpujara@gmail.com

Received: 04 December 2020

Revised: 14 January 2020

Accepted: 20 January 2020

Published: 30 May 2020

\section{Introduction}

Intestinal obstruction is a common clinical abnormality that is usually suspected on the basis of clinical signs and patient history. Intestinal obstruction is defined as mechanical or functional obstruction of the intestines which prevents the normal passage of the products of digestion. ${ }^{[1]}$ Intestinal obstruction is the most common surgical disorder of the small intestine. ${ }^{[2,3]}$ Though the knowledge of intestinal obstruction dates back to third to fourth century BC, it still remains important cause of morbidity and mortality in the surgical practice. The diagnosis of intestinal obstruction is often immediately evident after thorough clinical examination $\&$ plain radiography. ${ }^{[4]}$ But at times it poses a difficulty especially in patients presenting as SAIO with less severe, intermittent features that cause delay in diagnosis. So subacute intestinal obstruction remains a diagnostic \& therapeutic problem. ${ }^{[5-7]}$
The first imaging procedure used in patients with bowel obstruction is conventional radiography with $46-80 \%$ accuracy in determining the presence of obstruction. The next step in patients with indeterminate radiographic findings is radiography with intraluminal injection of contrast material. Its use should be avoided in patients with markedly diminished intestinal peristalsis. ${ }^{[8]}$ On ultrasonography, bowel obstruction is considered to be present when dilated loop measures $>2.5$ $\mathrm{cm}$ and length of segment is $>10 \mathrm{~cm}$. Coupled with clinical features, plain radiography can lead to conclusion in 46- 80\% cases. Ultrasound plays only adjunctive role to plain radiography. In such equivocal cases CT has been found to be very useful. On CT scan, small bowel diameter of more than $2.5 \mathrm{~cm}$ is indicative of obstruction. CT has particular advantage to detect exact level \& cause of obstruction. ${ }^{[9]}$ Now a day's CT is considered to be the most efficacious imaging technique for determining the cause of intestinal obstruction. However, the indications for the use of CT in patients with SAIO have not been 
fully defined. ${ }^{[10]}$ Accordingly, prospective study was done to determine the role of $\mathrm{CT}$ in the diagnosis of patients with suspected subacute bowel obstruction in whom confident decisions of therapy could not be made on the basis of clinical, plain radiographic \& ultrasound findings.

Objectives of the present study are: To study the role of CT in diagnosis of patients with suspected subacute intestinal obstruction (SAIO), to find out site \& cause of obstruction and to diagnose complications of obstruction.

\section{Subjects and Methods}

This study was conducted at Department of Radiodiagnosis, Gujarat Adani institute of Medcial Science, Bhuj, Kutch, Gujarat. Total number of 22 patients with SAIO having equivocal findings on USG was included in this study.

\section{Inclusion Criteria}

All patients presenting to surgery Out Patient Department or casualtywith the following features of Sub-Acute Intestinal Obstruction (SAIO) were included in the study:

Patients who had no substantial evidence of intestinal obstruction following sonographic and radiological evaluation

Patients with Intermittent/recurrent symptoms

\section{Exclusion Criteria}

Patients with severe systemic disease

Pregnant patients

All patients presenting to the Emergency and Out-Patient Department with features of intestinal obstruction were screened to identify the patients with SAIO. Detailed clinical evaluation of the patients was done. Plain x-ray of abdomen in erect posture \& abdomenopelvic ultrasound were performed before CT scan.

\section{Imaging Protocol}

CT scans were performed on a GE light speed VCT 64 slice scanner and acquired in pre contrast $\&$ portovenous phase at $60 \mathrm{sec}$ after i.v. contrast administration. Oral contrast agent liq. Sodium diatrizoate $30 \mathrm{ml}$ diluted in $1000 \mathrm{ml}$ of water was given over 45 minute sprior to scan.

Helical scanning was performed at $120 \mathrm{kVp} \& 240 \mathrm{~mA}$. Large FOV was used with scanning from diaphragm to beneath the symphysis pubis with helical speed $0.6 \mathrm{sec}$, slice thickness $5 \mathrm{~mm}$, interval $5 \mathrm{mmwhich}$ were used reconstruct $0.625 \mathrm{~mm}$ thickness axial $\&$ also coronal, sagittal images.

\section{Results}

We studied 22 patients of subacute intestinal obstruction with equivocal findings on plain radiography \& ultrasound. They

\begin{tabular}{|lll|}
\hline \multicolumn{3}{l}{ Table 1: Age wise distribution of study participants } \\
\hline Age in years & Number & Percentage (\%) \\
\hline $10-30$ & 9 & 40.9 \\
$40-60$ & 7 & 31.8 \\
\hline Above 60 & 6 & 27.2 \\
Total & 22 & 100 \\
\hline
\end{tabular}

\begin{tabular}{|lll|}
\hline \multicolumn{2}{l}{ Table 2: Gender wise distribution of study participants } \\
\hline Gender & Number & Percentage (\%) \\
\hline Male & 12 & 54.5 \\
Female & 10 & 45.4 \\
Total & 22 & 100 \\
\hline
\end{tabular}

\begin{tabular}{lll}
\hline \multicolumn{3}{l|}{ Table 3: Etiology of obstruction among study participants } \\
\hline $\begin{array}{l}\text { Cause of obstruc- } \\
\text { tion }\end{array}$ & Number & Percentage (\%) \\
\hline $\begin{array}{l}\text { Stricture } \\
\text { Intussusception }\end{array}$ & 8 & 36.3 \\
\hline $\begin{array}{l}\text { Bowel wall thicken- } \\
\text { ing }\end{array}$ & 3 & 27.2 \\
\hline Appendicitis & 2 & 13.6 \\
\hline $\begin{array}{l}\text { SMV thrombosis } \\
\text { with ilealgangrene }\end{array}$ & 1 & 9 \\
\hline $\begin{array}{l}\text { Jejunal perforation } \\
\text { Total }\end{array}$ & 2 & 4.5 \\
\hline
\end{tabular}

were subjected to CT scan \& our study findings are as follows: Age of the patients in the study range between 14 to 76 years. Out of 22 were 12 male \& 10 female patients. [Table 1,2] On CT scan all 22 patients were found to have obstruction with 19 patients having mechanical obstruction \& 3 patients having pseudo obstruction secondary to appendicitis, jejunal perforation. [Table 3] CT diagnoses of 20 out of 22 patients who underwent surgery \& biopsy were found to be correct on intraoperative findings. 2 patients were correctly diagnosed of strangulation with SMV thrombosis \& ileal gangrene which was confirmed intraoperatively.

The concordance between the operative findings and the CT scan findings was examined. CT scan correctly diagnosed intestinal obstruction with its cause in 20 out of 22 patients. Most common cause of SAIO was ileal stricture $38 \%$ followed by intussusceptions $23 \%$.

\section{Discussion}

SAIO has been defined in many ways and characteristically it suggests incomplete \& intermittent obstruction. ${ }^{[11]}$ It is 
characterized by continued passage of flatus and/or feces beyond 6-12 hrs. After onset of symptoms namely colicky abdominal pain, vomiting, and abdominal distension. ${ }^{[3]}$

The intestinal obstruction can be of small intestine or large intestine.

The causes of a small bowel obstruction can be divided into three categories:

Obstruction arising from extraluminal causes such as adhesions, hernias, carcinomas, and abscessesObstruction intrinsic to the bowel wall

Large bowel obstruction can be classified as dynamic (mechanical) or adynamic (pseudo-obstruction). Mechanical obstruction is characterized by blockage of the large bowel. Miscellaneous causes like intussusception, endometriosis, radiation enteropathy also comprise important cause of bowel obstruction. ${ }^{[6]}$

Usefulness of CT scan in diagnosis \& management of patients with SAIO is proven 18 and confirmed by the results of our study, in which CT diagnosis well correlated with final operative diagnosis in $93 \%$ of cases.

Age of the patients in the study range between 14 to 76 years. Out of 22 were 12 male \& 10 female patients. Randen V et al, conducted a prospective trial, Between March 2005 and November 2006, 1021 patients, 55\% female, mean age 47 years (range, 19-94 years), were included. ${ }^{[12]}$ In 117 of 1021 patients. Achiek MM et al studied a total of 105 adult patients, 65 males and 40 females. ${ }^{[13]} \mathrm{A}$ mean age of 46 years and an age range 22-75years for Juba patients and a mean age of 64 years with an age range 21-95 years for $\mathrm{KCH}$, London.

Amitojhaetal performed a study to evaluate role of investigations in diagnosis \& management of SAIO. ${ }^{[14]}$ Their study concluded that $\mathrm{CT}$ scan is highly useful in diagnosing SAIO. Accordingly we compared our study findings with theirs.

Our study confirmed the high sensitivity of CT scan in diagnosis of SAIO \& establishing its etiology. Similar results were obtained by Mallo RD et al who conducted a systemic review. ${ }^{[15]}$ This review was designed to describe the diagnostic performance of computed tomography $(\mathrm{CT})$ in assessing bowel ischemia and complete obstruction in small bowel obstruction (SBO). A MEDLINE search (1966-2004) identified 15 studies dealing with the $\mathrm{CT}$ diagnosis of ischemia and complete obstruction in SBO. Ischemia was defined by operative findings, and complete obstruction was defined by enteroclysis or operative findings. Aggregated sensitivity, specificity, and positive and negative predictive values (PPV and NPV) were calculated. Eleven of 15 studies reported on the $\mathrm{CT}$ diagnosis of ischemia in SBO based on 743 patients.

\section{Conclusion}

The findings of the study show that $\mathrm{CT}$ is a valuable diagnostic procedure in patients with subacute intestinal obstruction with high sensitivity. It is a problem-solving tool in equivocal cases. CT is not only useful in distinguishing mechanical obstruction from paralytic ileus but also it often establishes the cause of obstruction \& presence of complications like strangulation \& perforation. CT findings lead the surgeon to surgical management in significant number of patients.

\section{References}

1. Daddenavar VM, Mirji P, Kalburgi I. Clinical study of acute intestinal obstruction in tertiary care centre. Int Surg J. 2017;4(9):2903-2906. Available from: http://dx.doi.org/10. 18203/2349-2902.isj20173704.

2. Ray MS, Deepak BS. An unusual cause of sub-acute intestinal obstruction. Int Surg J. 2016;3(4):2310-2313. Available from: http://dx.doi.org/10.18203/2349-2902.isj20163621.

3. Whang EE, Zinner MJ, Intestine S. Small Intestine. In: BF C, editor. Schwartz principles of surgery. New York: McGraw Hill; 2005. p. 1017-54.

4. Chougule SR, RoteKaginalkar VJ. Role of CT in Evaluation uf Subacute Intestinal Obstruction with Inconclusive Radiographic \& Ultrasound Findings: A Prospective Study. Indian J Appl Res. 2018;8(4):25-27.

5. Gazelle GS, Goldberg MA, Wittenberg J, Halpern EF, Pinkney L, Mueller PR. Efficacy of CT in distinguishing small-bowel obstruction from other causes of small-bowel dilatation. Am J Roentgenol. 1994;162(1):43-47. Available from: https://dx. doi.org/10.2214/ajr.162.1.8273687.

6. Mallo RD, Salem L, Lalani T, Flum DR. Computed Tomography Diagnosis of Ischemia and Complete Obstruction in Small Bowel Obstruction: A Systematic Review. J Gastrointest Surg. 2005;9(5):690-694. Available from: https: //dx.doi.org/10.1016/j.gassur.2004.10.006.

7. van Randen A, Laméris W, Luitse JSK, Gorzeman M, Hesselink EJ, Dolmans DEJGJ, et al. The role of plain radiographs in patients with acute abdominal pain at the ED. Am J Emerg Med. 2011;29(6):582-589. Available from: https: //dx.doi.org/10.1016/j.ajem.2009.12.020.

8. Butt MU, Velmahos GC, Zacharias N, Alam HB, de Moya M, King DR. Adhesional Small Bowel Obstruction in the Absence of Previous Operations: Management and Outcomes. World J Surg. 2009;33(11):2368-2371. Available from: https: //dx.doi.org/10.1007/s00268-009-0200-6.

9. Frager D, Medwid SW, Baer JW, Mollinelli B, Friedman M. CT of small-bowel obstruction: value in establishing the diagnosis and determining the degree and cause. Am J Roentgenol. 1994;162(1):37-41. Available from: https://dx. doi.org/10.2214/ajr.162.1.8273686.

10. Balthazar EJ. George W. Holmes Lecture. CT of smallbowel obstruction. Am J Roentgenol . 1994;162(2):255-261. Available from: https://doi.org/10.2214/ajr.162.2.8310906.

11. Ullah S, Khan M, Mumtaz N, Naseer A. Intestinal Obstruction: A Spectrum of Causes. J Postgrad Med Inst. 2009;23(2):188192. 
12. van Randen A, Laméris W, Luitse JSK, Gorzeman M, Hesselink EJ, Dolmans DEJGJ, et al. The role of plain radiographs in patients with acute abdominal pain at the ED. Am J Emerg Med. 2011;29(6):582-589. Available from: https: //dx.doi.org/10.1016/j.ajem.2009.12.020.

13. Achiek MM, Tawad FK, Ladu JD. Where There Is No CT Scan Plain Abdominal X-Ray Suffices to Diagnose and Manage بدلا الأمعاء في الانسداد لنشخيص تكفي السينية الأشعة = Bowel Obstruction Sudan Med J. 2016;52(1):1-6. Available from: https://dx.doi.org/10.12816/0028215.

14. Ojha A, Jalaj A, Tiwari S, Mujalde V, Prasheel. Diagnosis and Management of Subacute Intestinal Obstruction: A Prospective Study. J Evolution Med Dent Sci. 2014;3(26):7326-7340. Available from: https://dx.doi.org/10.14260/jemds/2014/2898.

15. Mallo RD, Salem L, Lalani T, Flum DR. Computed Tomography Diagnosis of Ischemia and Complete Obstruction in Small Bowel Obstruction: A Systematic Review. Gastrointest Surg. 2005;9(5):690-694. Available from: https: //dx.doi.org/10.1016/j.gassur.2004.10.006.

Copyright: (C) the author(s), 2020. It is an open-access article distributed under the terms of the Creative Commons Attribution License (CC BY 4.0), which permits authors to retain ownership of the copyright for their content, and allow anyone to download, reuse, reprint, modify, distribute and/or copy the content as long as the original authors and source are cited.

How to cite this article: Pansuriya A. Role of Computed Tomography Scan in the Assessment of Subacute Intestinal Obstruction at Bhuj, Kutch: A Prospective Study. Asian J. Med. Radiol. Res. 2020;8(1):40-43.

DOI: dx.doi.org/10.47009/ajmrr.2020.8.1.8

Source of Support: Nil, Conflict of Interest: None declared. 